\title{
Toxic metal enrichment characteristics and sources of arid urban surface soil in Yinchuan City, China
}

\author{
ZHANG Mingxin ${ }^{1,2}$, LU Xinwei ${ }^{1 *}$, SHI Dongqi ${ }^{1}$, PAN Huiyun ${ }^{1,3}$ \\ ${ }^{1}$ Department of Environmental Science, School of Geography and Tourism, Shaanxi Normal University, Xi'an 710119, China; \\ ${ }^{2}$ School of Resource and Environment, Ningxia University, Yinchuan 750021, China; \\ ${ }^{3}$ Institute of Resources and Environment, Henan Polytechnic University, Jiaozuo 454000, China
}

\begin{abstract}
To investigate the environmental quality of the urban surface soil in Yinchuan City, the capital of Ningxia Hui Autonomous Region (Ningxia), China, we sampled surface soil and measured the concentrations of 8 toxic metals $(\mathrm{Pb}, \mathrm{Cr}, \mathrm{Cu}, \mathrm{Zn}, \mathrm{Co}, \mathrm{Bi}, \mathrm{Ni}$ and $\mathrm{V})$ using $\mathrm{X}$-ray fluorescence spectrometry. The enrichment characteristics and sources of these toxic metals in the soil were analyzed by the enrichment factor $(\mathrm{EF})$ and multivariate statistical analysis. The results showed that the mean concentrations of these toxic metals in the soil samples were 25.0, 109.1, 16.8, 26.0, 37.2, 2.7, 25.3 and $59.9 \mathrm{mg} / \mathrm{kg}$ for $\mathrm{Pb}, \mathrm{Cr}, \mathrm{Cu}$, $\mathrm{Zn}, \mathrm{Co}, \mathrm{Bi}, \mathrm{Ni}$ and $\mathrm{V}$, respectively, which were 1.2, 1.8, 0.8, 0.4, 3.2, 8.7, 0.7 and 0.8 times of the corresponding background values of Ningxia soil, respectively. The variations of $\mathrm{Pb}, \mathrm{Zn}, \mathrm{Co}, \mathrm{Bi}$ and $\mathrm{Ni}$ concentrations in the surface soil of Yinchuan were larger than those of the other metals. Our results also showed that the toxic metals investigated in the soil had different enrichment levels. Both Co and Bi were significantly enriched, whereas $\mathrm{Cr}$ was only moderately enriched in the soil. There was a deficiency or minimal enrichment of the other toxic metals in the soil. Source analysis results based on the concentration, enrichment characteristics and multivariate statistical analysis indicated that $\mathrm{Cr}, \mathrm{V}$ and $\mathrm{Ni}$ originated from a combination of fossil fuel combustion, traffic pollution and natural occurrence. $\mathrm{Pb}, \mathrm{Cu}$ and $\mathrm{Zn}$ were predominantly derived from natural and traffic sources, while $\mathrm{Co}$ and $\mathrm{Bi}$ primarily originated from construction sources.
\end{abstract}

Keywords: toxic metals; urban surface soil; enrichment factor; arid area; Northwest China

Citation: ZHANG Mingxin, LU Xinwei, SHI Dongqi, PAN Huiyun. 2018. Toxic metal enrichment characteristics and sources of arid urban surface soil in Yinchuan City, China. Journal of Arid Land, 10(4): 653-662. https://doi.org/10.1007/s40333-0180099-6

\section{Introduction}

Many cities have faced serious soil pollution issues due to rapid urbanization and industrialization, as well as the extensive growth in the use of motor vehicles. The continued increase in anthropogenic activities, including industrial production, traffic and domestic heating, have resulted in large amounts of pollutants being released into urban soil, which has led to an increase in soil pollution (Andersson et al., 2010; Ngole-Jeme, 2016). As one of the most important groups of pollutants in urban soil, toxic metals may originate from a range of sources, such as fossil fuel combustion, industrial discharges, construction dust, vehicular exhaust emissions and airborne particulates (Batjargal et al., 2010; Ngole-Jeme, 2016). Because toxic metals can accumulate in surface soil due to their non-degradability and durability (Batjargal et al., 2010; Yang et al., 2011),

\footnotetext{
${ }^{*}$ Corresponding author: LU Xinwei (E-mail: luxinwei@snnu.edu.cn)

Received 2017-05-31; revised 2017-12-01; accepted 2017-12-22

(C) Xinjiang Institute of Ecology and Geography, Chinese Academy of Sciences, Science Press and Springer-Verlag GmbH Germany, part of Springer Nature 2018
} 
soils have become an important sink for toxic metals and other pollutants in urban areas (Mielke et al., 1999). Extensive inputs of toxic metals can influence the natural geochemical cycling of the urban ecosystem and result in severe environmental soil contamination (Mielke et al., 1999; Batjargal et al., 2010; Papa et al., 2010; Yang et al., 2011).

As trace metals have accumulated in surface soil, investigations into their sources and effects have been undertaken. However, although numerous studies of toxic metal pollution in the urban surface soil have been conducted in developed countries over the last 10 years (Wilcke et al., 1998; Manta et al., 2002; Banat et al., 2005; Zhang, 2006; Morton-Bermea et al., 2009; Batjargal et al., 2010; Maas et al., 2010; Acosta et al., 2011; Tume et al., 2011), in some megacities of developing countries (Zhang et al., 2005; Shi et al., 2008; Xia et al., 2011), limited data is available regarding soil toxicity in the arid and semi-arid areas of Northwest China (Wang et al., 2016). These areas have experienced rapid urbanization and industrialization in recent years (Wang et al., 2016; Zhao et al., 2016), which has resulted in severe environmental problems (Lu et al., 2014).

Yinchuan is an important commercial city in Northwest China located on the New Eurasian Continental Bridge and the ancient Silk Road. Like other capital cities in China, urban construction and economic development in Yinchuan have occurred rapidly in recent decades, particularly since the implementation of the Chinese Great Western Development policy in the 1990s. With this rapid urbanization and industrialization, the urban population has increased in the city, and the influence of anthropogenic activities on the urban environment has become more intensive. However, there have been few studies of toxic metal pollution in the urban soil in Yinchuan, except for one study of farmland soil in Xingqing County (Wang et al., 2014). There is an urgent need to investigate the environmental quality of the urban soil. In this study, we investigated the concentrations and levels of accumulation of toxic metals in the topsoil of the city and identified their possible sources. The results will improve our understanding of soil contamination problems and assist in developing future environmental protection policies in similar arid areas.

\section{Materials and methods}

\subsection{Study area}

Yinchuan City, the capital of Ningxia Hui Autonomous Region, China, is situated in the center of the Ningxia Plain in the upper reaches of the Yellow River at an altitude of 1010-1150 m. The city has a typical temperate arid continental monsoon climate, with mean annual precipitation of 150 $200 \mathrm{~mm}$, annual mean temperature of $8^{\circ} \mathrm{C}-9^{\circ} \mathrm{C}$ and annual sunshine hours of $2800-3000 \mathrm{~h}$ (NMBS, 2013). The prevailing wind direction in autumn and winter is northwest, while in spring and summer it is southeast (NMBS, 2013). The main soil types are Sierozem and Aeolian. The urban area of Yinchuan, i.e., Xixia, Jinfeng and Xingqing districts, is about $756.6 \mathrm{~km}^{2}$. The urban population in 2013 was $2.12 \times 10^{6}$, with $5.1 \times 10^{5}$ motor vehicles being registered in the city in 2013 (NMBS, 2013). Yinchuan is one important area of education, culture, economy and manufacturing in Northwest China. The main industrial units are located in the western area (Xixia District) with the eastern area (Xinqing District) being dominated by the coal industry, coal-fired power generation, the construction industry, oil refining and the chemical industry.

\subsection{Sampling and experimental analysis}

Ninety-six surface soil samples were collected across Yinchuan (Fig. 1) using a grid method, which initially divided the research area into 77 grids of $3 \mathrm{~km} \times 3 \mathrm{~km}$. Soil sampling sites were located in the grid points, with composite surface soil samples $(0-15 \mathrm{~cm}$ depth) of approximately $1.5 \mathrm{~kg}$ being collected from the four corners of each grid using a stainless steel shovel in a $2 \mathrm{~m} \times 2 \mathrm{~m}$ sampling area. The exact longitude and latitude of each sampling site was recorded using a GPS (Magellan Triton 300-North America, San Dimas, CA, USA). All soil samples were stored in polythene bags, labeled, and taken to the laboratory for analysis. Soil samples were air-dried at room temperature before being passed through a $1.0-\mathrm{mm}$ nylon mesh to remove plant roots and small stones (Chen et al., 2012; Zhao et al., 2016). A 100-g sieved soil sample was taken from each soil sample and ground to less than $0.075 \mathrm{~mm}$. 
Wavelength dispersive X-ray fluorescence spectrometry (XRF, PW2403, PANalytical, Almelo, Netherlands) was used to determine the concentrations of $\mathrm{Pb}, \mathrm{Cr}, \mathrm{Cu}, \mathrm{Zn}, \mathrm{Co}, \mathrm{Bi}, \mathrm{Ni}$ and $\mathrm{V}$ in the soil samples. Following the methods used by Chen et al. (2012) and Lu et al. (2014), $2.0 \mathrm{~g}$ of boric acid and $4.0 \mathrm{~g}$ of milled soil sample were placed in a mold and pressed into a $32-\mathrm{mm}$ diameter pellet under a pressure of $30 \mathrm{t} / \mathrm{cm}^{2}$. Duplicate samples and standard samples (GSS1 and GSD-12) were measured simultaneously for quality control (Chen et al., 2012). The measured values of standard samples were $95 \%-102 \%$ of the certified values, and the relative standard deviations of the toxic metal concentrations in 10 duplicate samples were less than $5 \%$.

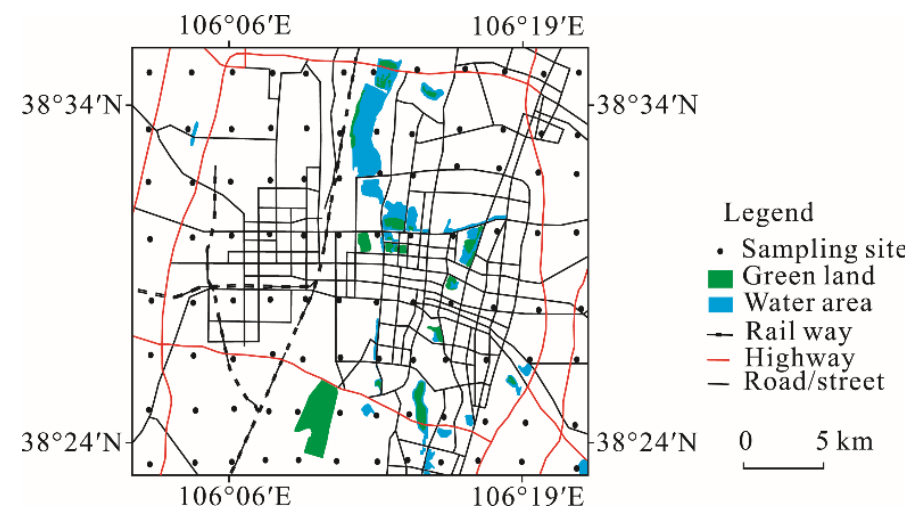

Fig. 1 Study area and sampling sites of urban topsoil in Yinchuan

\subsection{Enrichment factor (EF)}

To estimate the enrichment levels of the selected toxic metals in the samples, we used the following equation for calculating the EF of each metal (Chen et al., 2014):

$$
\mathrm{EF}=\frac{\left(C_{i} / C_{\text {ref }}\right)_{\text {sample }}}{\left(C_{i} / C_{\text {ref }}\right)_{\text {background }}},
$$

where $C_{i}$ is the concentration of toxic metal $i(\mathrm{mg} / \mathrm{kg})$ and $C_{\text {ref }}$ is the concentration of the reference element for normalization $(\mathrm{mg} / \mathrm{kg})$; sample is the investigated soil and background is Ningxia soil. In the EF calculation, $\mathrm{K}, \mathrm{Al}, \mathrm{Fe}, \mathrm{Mn}$, Ti and $\mathrm{Sr}$ are often used as reference elements because of their lack of variability in environmental samples (Han et al., 2006; Meza-Figueroa et al., 2007). The enrichment levels of toxic metals in the samples were classified according to the calculated EF values ( $\mathrm{Lu}$ et al., 2009; Chen et al., 2014): deficiency to minimal enrichment $(\mathrm{EF} \leq 2)$, moderate enrichment $(2<\mathrm{EF} \leq 5)$, significant enrichment $(5<\mathrm{EF} \leq 20)$, very high enrichment $(20<\mathrm{EF} \leq 40)$ and extremely high enrichment $(\mathrm{EF}>40)$. The $\mathrm{EF}$ value of a toxic metal can also reflect its source (Meza-Figueroa et al., 2007; Chen et al., 2014).

\subsection{Multivariate statistical analysis}

Correlation analysis, factor analysis (FA) and cluster analysis (CA) were executed using the SPSS19.0 software to determine the relationships among toxic metals in the soil samples and their possible sources. Correlation coefficients revealed the correlativity between each toxic metal (Tume et al., 2011). The FA can reduce complex variables and extract several factors for dissecting the relationships among the investigated variables (Han et al., 2006; Zhang, 2006; Meza-Figueroa et al., 2007; Chen et al., 2014). The CA can classify the toxic metals into two or more mutually exclusive groups based on the internal relationships between them (Facchinelli et al., 2001; Lu et al., 2010; Chen et al., 2014).

\section{Results and discussion}

\subsection{Toxic metal concentrations in the urban surface soil}

The toxic metal concentrations in soil across the study area and the background values in Ningxia 
soil are shown in Table 1. It was found that the $\mathrm{Cr}$, $\mathrm{Co}$ and $\mathrm{Bi}$ concentrations in all samples, and the $\mathrm{Pb}$ concentrations in $75 \%$ of samples were higher than their background values in Ningxia soil. The results for $\mathrm{Cu}, \mathrm{Zn}, \mathrm{Ni}$ and $\mathrm{V}$ in all samples were smaller than or close to their background values. The kurtosis values of $\mathrm{Pb}, \mathrm{Cr}$ and $\mathrm{Co}$ were larger than 0 , indicating that their distributions were steeper than normal (Chen et al., 2012). The skewness values of $\mathrm{Pb}$ and $\mathrm{Co}$ were larger than 1 , indicating that $\mathrm{Pb}$ and $\mathrm{Co}$ were positively skewed toward the lower concentrations (Lu et al., 2010; $\mathrm{Xia}$ et al., 2011). The coefficients of variation of $\mathrm{Pb}, \mathrm{Zn}, \mathrm{Co}, \mathrm{Bi}$ and $\mathrm{Ni}$ were relatively high $(>20 \%)$, with their maximum concentrations being more than 3 times of their minimum concentrations, indicating large variations in the concentrations of $\mathrm{Pb}, \mathrm{Zn}, \mathrm{Co}, \mathrm{Bi}$ and $\mathrm{Ni}$ in the surface soil of Yinchuan.

A comparison of the toxic metal concentrations in Yinchuan surface soil with reported levels for other cities (Table 2) showed that the $\mathrm{Cr}$ and Co concentrations were higher in Yinchuan. The $\mathrm{Cu}$ concentration in Yinchuan soil was lower than the values reported for other cities shown in Table 2, except for Shenzhen and Murcia. The Ni concentration in Yinchuan soil was higher than that

Table 1 Toxic metal concentrations in the urban surface soil of Yinchuan

\begin{tabular}{lrrrrrrrr}
\hline Item & $\mathrm{Co}$ & \multicolumn{1}{c}{$\mathrm{Cr}$} & $\mathrm{Cu}$ & $\mathrm{Ni}$ & $\mathrm{Pb}$ & $\mathrm{V}$ & $\mathrm{Zn}$ & $\mathrm{Bi}$ \\
\hline Minimum $(\mathrm{mg} / \mathrm{kg})$ & 16.7 & 66.2 & 11.3 & 11.0 & 12.8 & 35.9 & 11.6 & 0.8 \\
Maximum (mg/kg) & 108.4 & 143.8 & 23.6 & 36.1 & 49.1 & 76.7 & 47.3 & 4.7 \\
Mean (mg/kg) & 37.2 & 109.1 & 16.8 & 25.3 & 25.0 & 59.9 & 26.0 & 2.7 \\
$\mathrm{SD}(\mathrm{mg} / \mathrm{kg})$ & 17.4 & 12.8 & 2.9 & 5.8 & 5.4 & 10.0 & 7.8 & 0.8 \\
CV (\%) & 46.8 & 11.7 & 17.5 & 23.1 & 21.6 & 16.7 & 30.0 & 31.4 \\
Skewness & 1.7 & -0.3 & 0.4 & -0.6 & 1.5 & -0.7 & 0.4 & 0.0 \\
Kurtosis & 3.2 & 2.0 & -0.5 & -0.2 & 6.2 & -0.1 & -0.2 & -0.3 \\
Background value $(\mathrm{mg} / \mathrm{kg})^{\mathrm{a}}$ & 11.5 & 60.0 & 22.1 & 36.5 & 20.6 & 75.1 & 58.8 & 0.3 \\
\hline
\end{tabular}

Note: a , CNEMC (1999); SD, standard deviation; CV, coefficient of variation (CV=SD/Mean $\times 100)$.

Table 2 Toxic metal concentrations in the urban surface soils of Yinchan and other cities

\begin{tabular}{|c|c|c|c|c|c|c|c|c|c|}
\hline \multirow{2}{*}{ City } & $\mathrm{Co}$ & $\mathrm{Cr}$ & $\mathrm{Cu}$ & $\mathrm{Ni}$ & $\mathrm{Pb}$ & $\mathrm{V}$ & $\mathrm{Zn}$ & $\mathrm{Bi}$ & \multirow{2}{*}{ Reference } \\
\hline & \multicolumn{8}{|c|}{$(\mathrm{mg} / \mathrm{kg})$} & \\
\hline Changchun & NA & 66.0 & 29.4 & NA & 35.4 & NA & 90.0 & NA & Yang et al. (2011) \\
\hline Nanjing & NA & 84.7 & 66.1 & NA & 107.3 & NA & 162.6 & NA & Lu et al. (2003) \\
\hline Beijing & NA & 60.3 & 34.4 & 25.9 & 39.5 & NA & 89.6 & NA & Xia et al. (2011) \\
\hline Shanghai & NA & 107.9 & 59.3 & 31.1 & 70.7 & NA & 301.4 & NA & Shi et al. (2008) \\
\hline Hong Kong & 3.6 & 17.8 & 16.2 & 4.1 & 88.1 & NA & 103.0 & NA & Lee et al. (2006) \\
\hline Shenyang & NA & NA & 51.3 & NA & 75.3 & NA & 138.0 & NA & Sun et al. (2010) \\
\hline Hangzhou & NA & 63.3 & 46.1 & NA & 84.3 & NA & 202.5 & NA & Lu and Bai (2006) \\
\hline Xi'an & 19.3 & 81.1 & 54.3 & 34.5 & 59.7 & 186.2 & 85.2 & NA & Chen et al. (2012) \\
\hline Mexico & NA & 117.0 & 100.8 & 39.8 & 140.5 & NA & 306.7 & NA & Morton-Bermea et al. (2009) \\
\hline Ulaanbaatar & NA & 20.3 & 35.9 & 18.7 & 63.9 & NA & 158.7 & NA & Batjargal et al. (2010) \\
\hline Central Catalonia & NA & 24.6 & 24.0 & 22.8 & 23.3 & 51.5 & 76.0 & NA & Tume et al. (2011) \\
\hline Annaba & NA & 30.9 & 39.0 & NA & 53.1 & NA & 67.5 & NA & Maas et al. (2010) \\
\hline Damascus Ghouta & 13.0 & 57.0 & 34.0 & 39.0 & 17.0 & NA & 103.0 & NA & Möller et al. (2005) \\
\hline Bangkok & NA & 26.4 & 41.7 & 24.8 & 47.8 & NA & 118.0 & NA & Wilcke et al. (1998) \\
\hline Naples & NA & 11.0 & 74.0 & NA & 262.0 & NA & 251.0 & NA & Imperato et al. (2003) \\
\hline Galway & 6.0 & 35.0 & 27.0 & 22.0 & 58.0 & 50.0 & 85.0 & NA & Zhang (2006) \\
\hline Murcia & NA & 16.3 & 8.9 & 11.1 & 21.9 & NA & 16.6 & NA & Acosta et al. (2011) \\
\hline Jordan & NA & 83.9 & NA & NA & 62.2 & NA & 146.9 & NA & Banat et al. (2005) \\
\hline Palermo & 6.5 & 39.0 & 77.0 & 19.1 & 253.0 & 5.1 & 151.0 & NA & Manta et al. (2002) \\
\hline Madrid & 6.4 & 74.7 & 71.7 & 14.1 & 161.0 & 30.0 & 210.0 & NA & De Miguel et al. (1998) \\
\hline Yinchuan & 37.2 & 109.1 & 16.8 & 25.3 & 25.0 & 59.9 & 26.0 & 2.7 & This work \\
\hline
\end{tabular}

Note: NA, not available. 
reported for other cities, except for Beijing, Shanghai, Changsha and Chengdu. The $\mathrm{Pb}$ concentration was lower than that reported for other cities, except for Murcia, Damascus Ghouta and central Catalonia. The V concentration was higher than that recorded in other cities, except for Chengdu and Xi'an. The Zn concentration was lower in Yinchuan than was reported in the other cities. The difference in toxic metal concentrations in urban soils from different cities may be related to the different soil types, natural environmental conditions, the intensity of anthropogenic activity and urban environmental planning and management.

\subsection{Enrichment characteristics of toxic metals in the soil}

Figure 2 shows the EF values of all toxic metals measured in the soil samples relative to the background values of local soil (CNEMC, 1990), with K as the reference element. The EF values of $\mathrm{Pb}, \mathrm{Cr}, \mathrm{Cu}, \mathrm{Zn}, \mathrm{Co}, \mathrm{Bi}, \mathrm{Ni}$ and $\mathrm{V}$ ranged from 0.7 to $3.1,1.6$ to $3.1,0.6$ to $1.3,0.2$ to $1.0,1.6$ to $13.2,3.2$ to $18.8,0.4$ to 1.3 and 0.7 to 1.4 , with mean values of $1.5,2.3,0.9,0.5,4.1,10.9,0.9$ and 1.0 , respectively. The EF values of $\mathrm{Cu}, \mathrm{Zn}, \mathrm{Ni}$ and $\mathrm{V}$ in all soil samples, and $\mathrm{Pb}$ in $96 \%$ of samples, did not exceed 2.0, indicating deficiency to minimal enrichment. The mean EF (4.1) and 75\% EF of Co ranged between 2.0 and 5.0, indicating a moderate enrichment in the samples, while $22 \%$ and $3 \%$ of samples had significant enrichment, and deficiency to minimal enrichment, respectively. The mean EF (2.3) and 91\% EF of $\mathrm{Cr}$ ranged between 2.0 and 5.0, indicating a moderate enrichment. The $96 \% \mathrm{EF}$ for $\mathrm{Bi}$ was in the range of 5.0-20.0, with a mean larger than 10.0, indicating an significant enrichment. Based on the EF results, it was concluded that $\mathrm{Cu}, \mathrm{Zn}, \mathrm{Ni}$ and $\mathrm{V}$ in Yinchuan surface soils were mainly affected by natural sources, $\mathrm{Pb}$ was mainly affected by natural sources and partly influenced by anthropogenic activities, while $\mathrm{Co}, \mathrm{Cr}$ and $\mathrm{Bi}$ were mainly affected by anthropogenic activities.

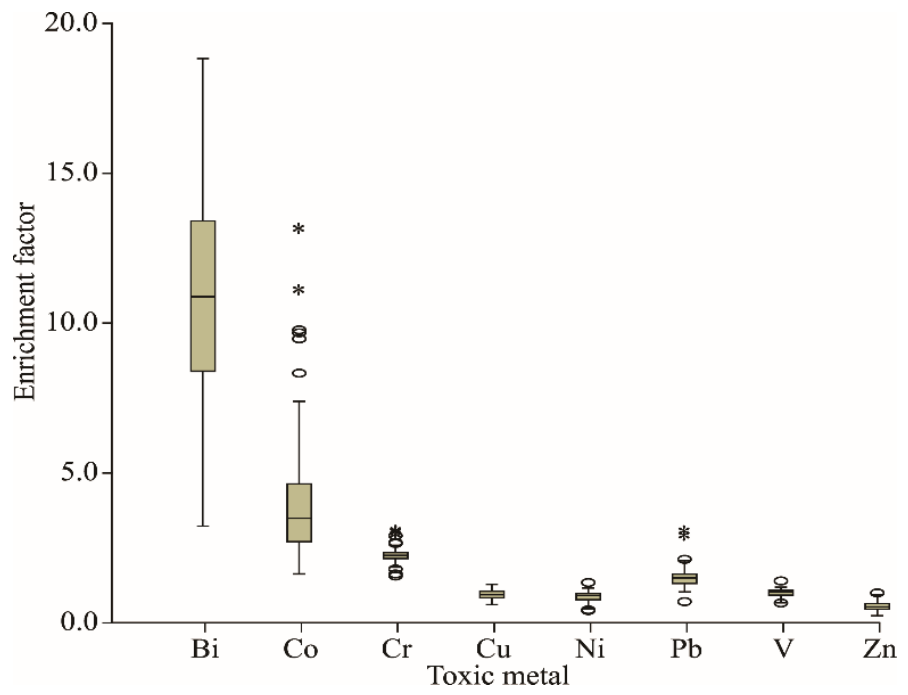

Fig. 2 Box-plot of enrichment factor for toxic metals in the urban surface soil of Yinchuan. *, extreme outlier; o, mid outlier.

\subsection{Results of the multivariate statistical analysis}

The correlation analysis results for toxic metals in the surface soil of Yinchuan (Table 3) showed that $\mathrm{Pb}, \mathrm{Cr}, \mathrm{Cu}, \mathrm{Zn}, \mathrm{Ni}$ and $\mathrm{V}$ concentrations were significantly and positively correlated with each other $(P<0.01)$, indicating similar influencing factors (Lu et al., 2010; Saeedi et al., 2012). The Co concentration was negatively correlated with the concentrations of these metals, implying that the sources of Co differed from the sources of $\mathrm{Pb}, \mathrm{Cr}, \mathrm{Cu}, \mathrm{Zn}, \mathrm{Ni}$ and $\mathrm{V}$. The Bi concentration was positively correlated with that of $\mathrm{Co}(P<0.05)$ and negatively correlated with the concentrations of the other metals, indicating that $\mathrm{Bi}$ and Co had similar sources that differed from those of the other metals.

The factor analysis (FA) results showed that three factors accounted for $79.9 \%$ of the total 
variance (Table 4). Factor 1 was primarily loaded by $\mathrm{Cr}$, $\mathrm{Co}, \mathrm{Ni}$ and $\mathrm{V}$ and moderately by $\mathrm{Pb}$, accounting for $39.4 \%$ of the total variance. The $\mathrm{Pb}$ loading $(0.581)$ was smaller than the loading for the other four metals, implying a quasi-independent behavior in the group. The Co loading $(-0.869)$ in Factor 1 indicated that this metal was negatively correlated with Factor 1. Factor 2, dominated by $\mathrm{Cu}, \mathrm{Pb}$ and $\mathrm{Zn}$, accounted for $27.5 \%$ of the total variance. Factor 3 was loaded by $\mathrm{Bi}$ and accounted for $13.9 \%$ of the total variance. Both Bi and Co were negatively correlated with Factor 1 and Factor 2, and positively correlated with Factor 3, although the Co loading (0.093) in Factor 3 was small. The relationship among the toxic metals on the basis of the first three factors is shown in Figure 3.

A cluster distance of 5-10 was used in the hierarchical CA of toxic metal concentrations in surface soil (Fig. 4), with results showing three clusters, $\mathrm{Cr}-\mathrm{Ni}-\mathrm{V}, \mathrm{Pb}-\mathrm{Cu}-\mathrm{Zn}$ and $\mathrm{Co}-\mathrm{Bi}$. These results were in accordance with the FA results. It is also evident that clusters 1 and 2 merged at a relatively higher level, suggesting these metals were derived from the same source.

Table 3 Pearson's correlation matrix of toxic metal concentrations in the urban surface soil of Yinchuan

\begin{tabular}{ccccccccc}
\hline & $\mathrm{Co}$ & $\mathrm{Cr}$ & $\mathrm{Cu}$ & $\mathrm{Ni}$ & $\mathrm{Pb}$ & $\mathrm{V}$ & $\mathrm{Zn}$ & $\mathrm{Bi}$ \\
\hline $\mathrm{Co}$ & & 0.000 & 0.027 & 0.000 & 0.000 & 0.000 & 0.000 & 0.043 \\
$\mathrm{Cr}$ & $-0.482^{* *}$ & & 0.000 & 0.000 & 0.000 & 0.000 & 0.000 & 0.185 \\
$\mathrm{Cu}$ & $-0.226^{*}$ & $0.417^{* *}$ & & 0.000 & 0.000 & 0.000 & 0.000 & 0.619 \\
$\mathrm{Ni}$ & $-0.659^{* *}$ & $0.596^{* *}$ & $0.498^{* *}$ & & 0.000 & 0.000 & 0.000 & 0.047 \\
$\mathrm{~Pb}$ & $-0.513^{* *}$ & $0.605^{* *}$ & $0.549^{* *}$ & $0.722^{* *}$ & & 0.000 & 0.000 & 0.059 \\
$\mathrm{~V}$ & $-0.691^{* *}$ & $0.612^{* *}$ & $0.432^{* *}$ & $0.965^{* *}$ & $0.659^{* *}$ & & 0.000 & 0.108 \\
$\mathrm{Zn}$ & $-0.421^{* *}$ & $0.426^{* *}$ & $0.607^{* *}$ & $0.569^{* *}$ & $0.624^{* *}$ & $0.572^{* *}$ & 0.978 \\
$\mathrm{Bi}$ & $0.207^{*}$ & -0.136 & -0.051 & $-0.204^{*}$ & -0.194 & -0.165 & -0.003 & \\
\hline
\end{tabular}

Note: The left lower part is correlation coefficient and the right upper part is significant level. ${ }^{*}$, significant correlation at $P<0.05$ level (two-tailed); ${ }^{* *}$, significant correlation at $P<0.01$ level (two-tailed).

Table 4 Rotated component matrix for toxic metal concentrations in the urban surface soil of Yinchuan

\begin{tabular}{lcccc}
\hline \multirow{2}{*}{ Element } & \multicolumn{2}{c}{ Factor } & Communalities \\
\cline { 2 - 4 } $\mathrm{Bi}$ & 1 & 2 & 0.987 & 0.989 \\
$\mathrm{Co}$ & -0.124 & -0.007 & 0.093 & 0.766 \\
$\mathrm{Cr}$ & -0.869 & -0.041 & -0.077 & 0.555 \\
$\mathrm{Cu}$ & 0.631 & 0.389 & -0.044 & 0.846 \\
$\mathrm{Ni}$ & 0.127 & 0.910 & -0.099 & 0.877 \\
$\mathrm{~Pb}$ & 0.839 & 0.403 & -0.150 & 0.740 \\
$\mathrm{~V}$ & 0.581 & 0.616 & -0.045 & 0.890 \\
$\mathrm{Zn}$ & 0.881 & 0.333 & -0.101 & 0.727 \\
$\mathrm{Eigenvalue}$ & 0.388 & 0.753 & 1.03 & 13.0 \\
Total variance explained (\%) & 3.15 & 2.20 & 79.9 & \\
Cumulative (\%) & 39.4 & 27.5 & 66.9 & \\
\hline
\end{tabular}

\subsection{Sources of toxic metals}

The correlation analysis results showed that $\mathrm{Cr}$, Ni and $\mathrm{V}$ concentrations were significantly and positively correlated. The FA and CA results for these metals showed that they were clearly separated from the other metals; thus, indicating that $\mathrm{Cr}$, Ni and $\mathrm{V}$ had similar sources. The $\mathrm{Cr}$ results had an EF value of 1.0-10.0, and its concentration was 1.1-2.4 times of the background value of Ningxia soil, implying a combination of natural and anthropogenic influences on the $\mathrm{Cr}$ concentration (Han et al., 2006). Elevated concentrations of $\mathrm{Cr}$ were previously reported in the areas surrounding coal-fired power plants (Chen et al., 2014), while $\mathrm{Cr}$ is widely used in aluminum alloys, titanium alloys and automobile parts (Madany et al., 1994). These previous findings concur with our results, with surface soil samples containing high concentrations of $\mathrm{Cr}$ (more than 2.0 


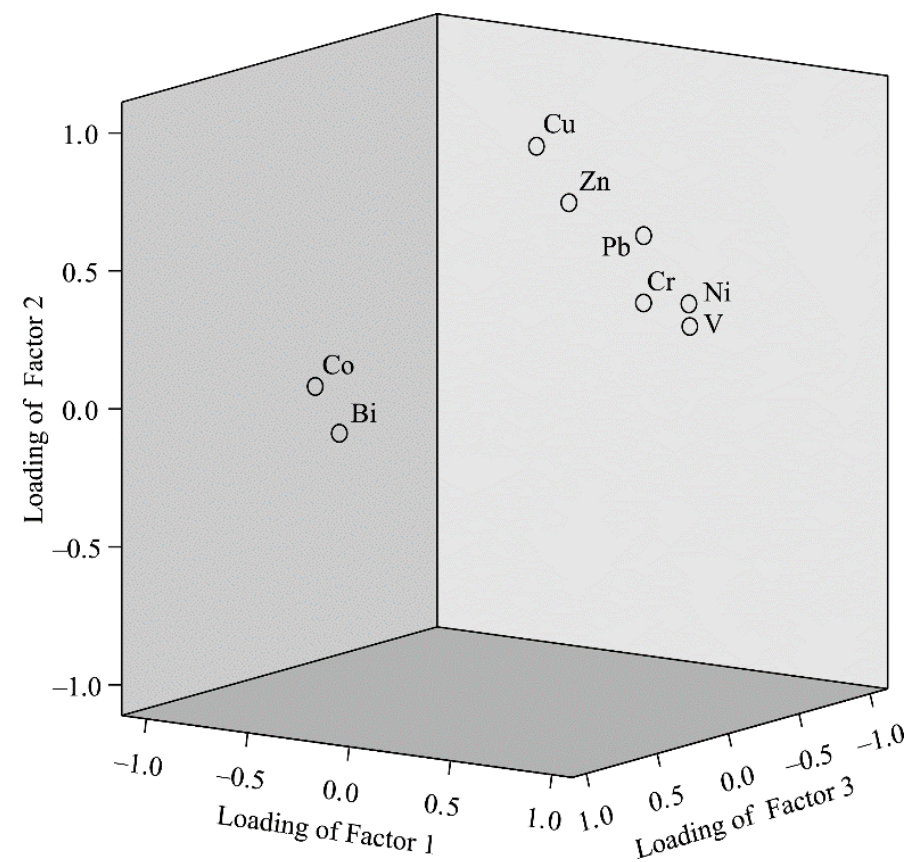

Fig. 3 Factor analysis results in the three-dimensional space: plot of loading of the three factors

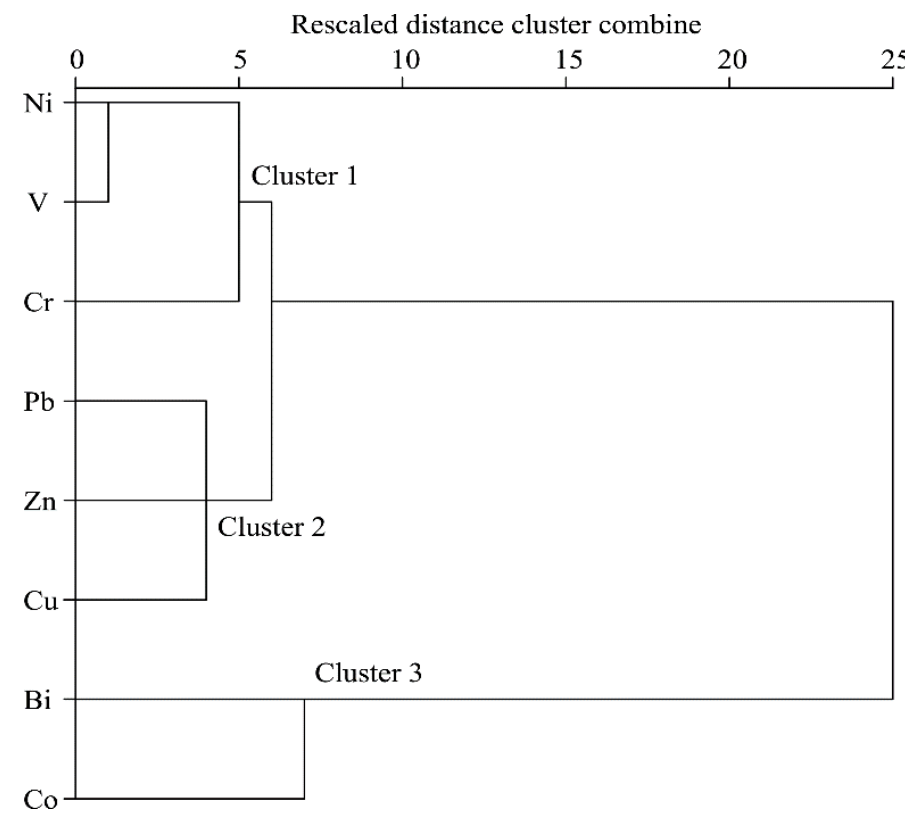

Fig. 4 Cluster analysis dendrogram of 8 toxic metals based on Ward method

times of the background value) primarily distributed in the areas surrounding the coal-fired power plant and automotive plant in the Xixia District of western Yinchuan, and also located close to roads with a high traffic density. Considering the concentration, EF and area where high concentrations were distributed, we concluded that $\mathrm{Cr}$ in the surface soil originated from traffic emissions, fossil fuel combustion and natural sources. The $\mathrm{Ni}$ and $\mathrm{V}$ concentrations in the soil samples were close to or smaller than the background values in Ningxia soil. Their EF values in most samples were close to 1, and the samples collected near the coal-fired power plant contained higher $\mathrm{Ni}$ and $\mathrm{V}$ concentrations than samples collected elsewhere in the city. These results indicated that $\mathrm{Ni}$ and $\mathrm{V}$ in the surface soil principally originated from natural sources, partially from fossil 
fuel combustion.

The correlation analysis results for $\mathrm{Pb}, \mathrm{Cu}$ and $\mathrm{Zn}$ indicated strongly positive correlations. These metals belonged to the same component in the FA and were also classified together in the CA. The $\mathrm{Cu}$ and $\mathrm{Zn}$ concentrations in the soil samples were close to or lower than their corresponding background values in Ningxia soil and their EF values were close to or smaller than 1, indicating that they were predominantly derived from natural sources. The $\mathrm{Pb}$ concentrations in $75 \%$ of soil samples were more than 1.1 times the background values in Ningxia soil and its EF values in $60 \%$ of soil samples were more than 1.5, demonstrating the influence of anthropogenic activities. Soil samples collected adjacent to the main road, which had a high traffic density, had higher $\mathrm{Pb}$ concentrations than samples collected close to small roads. Previous studies have demonstrated that vehicle emissions were the main source of $\mathrm{Pb}$ in urban soil (Hewitt and Rashed, 1990; Christoforidis and Stamatis, 2009; Yang et al., 2011; Chen et al., 2012), which was also apparent from the samples in Yinchuan, with the number of private cars in the city increasing rapidly in recent years. The results for $\mathrm{Pb}, \mathrm{Cu}$ and $\mathrm{Zn}$ confirmed that these metals mainly originated from both natural and traffic sources. Furthermore, the results of the correlation analysis (Table 3 ) and $\mathrm{CA}$ (Fig. 4) demonstrated that $\mathrm{Pb}, \mathrm{Cr}, \mathrm{Cu}, \mathrm{Zn}, \mathrm{Ni}$ and $\mathrm{V}$ had similar sources, i.e., the combined effects of natural inputs and traffic sources.

The results of the correlation analysis, FA and $\mathrm{CA}$ indicated that $\mathrm{Co}$ and $\mathrm{Bi}$ were derived from similar sources. Their concentrations in the soil samples were 1.5-9.4 and 2.6-15.2 times of the corresponding background values of Ningxia soil, with a moderate and significant enrichment in the surface soil, respectively. The $6 \% \mathrm{EF}$ of $\mathrm{Co}$ and $64 \% \mathrm{EF}$ of $\mathrm{Bi}$ were larger than or close to 10.0 , indicating that $\mathrm{Co}$ and $\mathrm{Bi}$ concentrations in the topsoil were influenced by local anthropogenic sources. Previous investigations have shown that Co pollution in the urban environment was primarily derived from construction sources ( $\mathrm{Lu}$ et al., 2010; Chen et al., 2014), with Co and Bi being widely used in paints, pigments and coating materials (Lu et al., 2010). Surface soil samples from our study collected near construction sites and building demolition sites in Yinchuan contained higher concentrations of $\mathrm{Co}$ and $\mathrm{Bi}$ (more than 5 times of the background values); thus, we can conclude that $\mathrm{Co}$ and $\mathrm{Bi}$ in surface soil samples also mainly originated from construction sources.

\section{Conclusions}

The mean concentrations of $\mathrm{Pb}, \mathrm{Cr}, \mathrm{Cu}, \mathrm{Zn}, \mathrm{Co}, \mathrm{Bi}, \mathrm{Ni}$ and $\mathrm{V}$ in the surface soil of Yinchuan were $25.0,109.1,16.8,26.0,37.2,2.7,25.3$ and $59.9 \mathrm{mg} / \mathrm{kg}$, respectively. There was a moderate enrichment of $\mathrm{Cr}$ and $\mathrm{Co}$ in the surface soil, while there was a deficiency to minimal enrichment of $\mathrm{Pb}, \mathrm{Cu}, \mathrm{Zn}, \mathrm{Ni}$ and $\mathrm{V}$. Bismuth was significantly enriched. The comprehensive analyses of toxic metal concentrations and enrichment levels, as well as a correlation analysis, FA and CA indicated that $\mathrm{Cr}$, $\mathrm{Ni}$ and $\mathrm{V}$ were derived from mixed sources of traffic pollution, fossil fuel combustion and natural processes; $\mathrm{Pb}, \mathrm{Cu}$ and $\mathrm{Zn}$ were principally derived from natural and traffic sources, while $\mathrm{Co}$ and $\mathrm{Bi}$ were mainly derived from construction sources.

\section{Acknowledgements}

This research was supported by the National Natural Science Foundation of China $(41271510,41461098)$ and the Fundamental Research Funds for the Central Universities of China (GK201601009, 2017TS027). All experiments were finished in the Environmental Science Lab of Shaanxi Normal University. We thank LYU Ruipeng, LIU Jufeng, YU Guoliang and YAN Chang for their helps with the sampling.

\section{References}

Acosta J A, Faz A, Martínez-Martínez S, et al. 2011. Enrichment of metals in soils subjected to different land uses in a typical Mediterranean environment (Murcia city, southeast Spain). Applied Geochemistry, 26(2): 405-414.

Andersson M, Ottesen R T, Langedal M. 2010. Geochemistry of urban surface soils-Monitoring in Trondheim, Norway. Geoderma, 156(3-4): 112-118. 
Banat K M, Howari F M, Al-Hamad A A. 2005. Heavy metals in urban soils of central Jordan: Should we worry about their environmental risks? Environmental Research, 97(3): 258-273.

Batjargal T, Otgonjargal E, Baek K, et al. 2010. Assessment of metals contamination of soils in Ulaanbaatar, Mongolia. Journal of Hazardous Materials, 184(1-3): 872-876.

Chen H, Lu X W, Li L Y, et al. 2014. Metal contamination in campus dust of Xi'an, China: A study based on multivariate statistics and spatial distribution. Science of the Total Environment, 484: 27-35.

Chen X D, Lu X W, Yang G. 2012. Sources identification of heavy metals in urban topsoil from inside the Xi'an Second Ringroad, NW China using multivariate statistical methods. CATENA, 98: 73-78.

China National Environmental Monitoring Center (CNEMC). 1990. The Background Values of Elements in Chinese Soils. Beijing: Environmental Science Press of China, 338-379. (in Chinese)

Christoforidis A, Stamatis N. 2009. Heavy metal contamination in street dust and roadside soil along the major national road in Kavala's region, Greece. Geoderma, 151(3-4): 257-263.

De Miguel E, De Grado M J, Llamas J F, et al. 1998. The overlooked contribution of compost application to the trace element load in the urban soil of Madrid (Spain). Science of the Total Environment, 215(1-2): 113-122.

Facchinelli A, Sacchi E, Mallen L. 2001. Multivariate statistical and GIS-based approach to identify heavy metal sources in soils. Environmental Pollution, 114(3): 313-324.

Han Y M, Du P X, Cao J J, et al. 2006. Multivariate analysis of heavy metal contamination in urban dusts of Xi'an, Central China. Science of the Total Environment, 355(1-3): 176-186.

Hewitt C N, Rashed M B. 1990. An integrated budget for selected pollutants for a major rural highway. Science of the Total Environment, 93: 375-384.

Imperato M, Adamo P, Naimo D, et al. 2003. Spatial distribution of heavy metals in urban soils of Naples city (Italy). Environmental Pollution, 124(2): 247-256.

Lee C S L, Li X D, Shi W Z, et al. 2006. Metal contamination in urban, suburban, and country park soils of Hong Kong: a study based on GIS and multivariate statistics. Science of the Total Environment, 356(1-3): 45-61.

Lu S G, Bai S Q. 2006. Study on the correlation of magnetic properties and heavy metals content in urban soils of Hangzhou City, China. Journal of Applied Geophysics, 60(1): 1-12.

Lu X W, Li L Y, Wang L J, et al. 2009. Contamination assessment of mercury and arsenic in roadway dust from Baoji, China. Atmospheric Environment, 43(15): 2489-2496.

Lu X W, Wang L J, Li L Y, et al. 2010. Multivariate statistical analysis of heavy metals in street dust of Baoji, NW China. Journal of Hazardous Materials, 173(1-3): 744-749.

Lu X W, Wu X, Wang Y W, et al. 2014. Risk assessment of toxic metals in street dust from a medium-sized industrial city of China. Ecotoxicology and Environmental Safety, 106: 154-163.

Lu Y, Gong Z T, Zhang G L, et al. 2003. Concentrations and chemical speciations of $\mathrm{Cu}, \mathrm{Zn}, \mathrm{Pb}$ and $\mathrm{Cr}$ of urban soils in Nanjing, China. Geoderma, 115(1-2): 101-111.

Maas S, Scheifler R, Benslama M, et al. 2010. Spatial distribution of heavy metal concentrations in urban, suburban and agricultural soils in a Mediterranean city of Algeria. Environmental Pollution, 158(6): 2294-2301.

Madany I M, Akhter M S, Jowder O A A. 1994. The correlations between heavy metals in residential indoor dust and outdoor street dust in Bahrain. Environment International, 20(4): 483-492.

Manta D S, Angelone M, Bellanca A, et al. 2002. Heavy metals in urban soils: a case study from the city of Palermo (Sicily), Italy. Science of the Total Environment, 300(1-2): 229-243.

Meza-Figueroa D, De La O-Villanueva M, De La Parra M L. 2007. Heavy metal distribution in dust from elementary schools in Hermosillo, Sonora, México. Atmospheric Environment, 41(2): 276-288.

Mielke H W, Gonzales C R, Smith M K, et al. 1999. The urban environment and children's health: soils as an integrator of lead, zinc, and cadmium in New Orleans, Louisiana, U.S.A. Environmental Research, 81(2): 117-129.

Möller A, Müller H W, Abdullah A, et al. 2005. Urban soil pollution in Damascus, Syria: concentrations and patterns of heavy metals in the soils of the Damascus Ghouta. Geoderma, 124(1-2): 63-71.

Morton-Bermea O, Hernández-Álvarez E, González-Hernández G, et al. 2009. Assessment of heavy metal pollution in urban topsoils from the metropolitan area of Mexico City. Journal of Geochemical Exploration, 101(3): 218-224.

Ngole-Jeme V M. 2016. Heavy metals in soils along unpaved roads in south west Cameroon: Contamination levels and health risks. Ambio, 45(3): 374-386.

Ningxia Municipal Bureau of Statistics (NMBS). 2013. Ningxia Statistical Yearbook. Beijing: China Statistics Press, 31-50. (in Chinese)

Papa S, Bartoli G, Pellegrino A, et al. 2010. Microbial activities and trace element contents in an urban soil. Environmental 
Monitoring and Assessment, 165(1-4): 193-203.

Saeedi M, Li LY, Salmanzadeh M. 2012. Heavy metals and polycyclic aromatic hydrocarbons: Pollution and ecological risk assessment in street dust of Tehran. Journal of Hazardous Materials, 227-228: 9-17.

Shi G T, Chen Z L, Xu S Y, et al. 2008. Potentially toxic metal contamination of urban soils and roadside dust in Shanghai, China. Environmental Pollution, 156(2): 251-260.

Sun Y B, Zhou Q X, Xie X K, et al. 2010. Spatial, sources and risk assessment of heavy metal contamination of urban soils in typical regions of Shenyang, China. Journal of Hazardous Materials, 174(1-3): 455-462.

Tume P, Bech J, Reverter F, et al. 2011. Concentration and distribution of twelve metals in central Catalonia surface soils. Journal of Geochemical Exploration, 109(1-3): 92-103.

Wang W, Lai Y S, Ma Y Y, et al. 2016. Heavy metal contamination of urban topsoil in a petrochemical industrial city in Xinjiang, China. Journal of Arid Land, 8(6): 871-880.

Wang Y Q, Bai Y R, Wang J Y. 2014. Distribution of soil heavy metal and pollution evaluation on the different sampling scales in farmland on Yellow River irrigation area of Ningxia: a case study in Xingqing county of Yinchuan city. Environmental Science, 35(7): 2714-2720. (in Chinese)

Wilcke W, Müller S, Kanchanakool N, et al. 1998. Urban soil contamination in Bangkok: heavy metal and aluminium partitioning in topsoils. Geoderma, 86(3-4): 211-228.

Xia X H, Chen X, Liu R M, et al. 2011. Heavy metals in urban soils with various types of land use in Beijing, China. Journal of Hazardous Materials, 186(2-3): 2043-2050.

Yang Z P, Lu W X, Long Y Q, et al. 2011. Assessment of heavy metals contamination in urban topsoil from Changchun City, China. Journal of Geochemical Exploration, 108(1): 27-38.

Zhang C S. 2006. Using multivariate analyses and GIS to identify pollutants and their spatial patterns in urban soils in Galway, Ireland. Environmental Pollution, 142(3): 501-511.

Zhang G L, Yang F G, Zhao Y G, et al. 2005. Historical change of heavy metals in urban soils of Nanjing, China during the past 20 centuries. Environment International, 31(6): 913-919.

Zhao N, Lu X W, Chao S G. 2016. Risk assessment of potentially toxic elements in smaller than 100- $\mu$ m street dust particles from a valley-city in northwestern China. Environmental Geochemistry and Health, 38(2): 483-496. 